\title{
Influence of twist drill geometry on chip split with self vibratory drilling head
}

\author{
OlCAY ÖNDER ${ }^{1, a}$, Henri PARIS ${ }^{1}$ AND JOËL RECH ${ }^{2}$ \\ 1 G-SCOP, 46 Av. Felix Viallet, 38041 Grenoble Cedex 1, France \\ 2 LTDS, 58 Av. Jean Parot, 42000 St Étienne, France
}

Received 30 September 2011, Accepted 28 January 2012

\begin{abstract}
In industrial area, drilling is one of the most commonly used machining operations. Today, conventional drilling methods have found their limits in deep hole drilling. To be able to push these limits, we have developed a new technology: vibratory drilling. The aim of this study is to determine the influence of the twist drill geometry on performance of the self vibratory drilling head. For that reason, it is necessary to identify the geometrical properties which have the strongest influence on axial vibrations of twist drill and on chip fragmentation. Moreover, we have also validated the experimental results by a simulator which can predict the behaviour of the self vibratory drilling head by taking into account geometrical defects of the tool.
\end{abstract}

Key words: Drilling / drill geometry / self-vibratory drilling / chatter

Résumé - Influence de la géometrie du foret sur le fractionnement du copeau en perçage vibratoire. Le perçage est une opération couramment utilisée en usinage. Aujourd'hui, les méthodes de perçage conventionnelles trouvent leurs limites en perçage profond. Pour repousser ces limites, nous avons développé une nouvelle technologie : le perçage vibratoire. L'objectif de cet article est d'étudier l'influence de la géométrie du foret sur le comportement de la tête de perçage vibratoire auto-entretenu. Il s'agit d'identifier les éléments géométriques qui ont une forte influence sur la génération des vibrations axiales $\mathrm{du}$ foret et donc sur une bonne fragmentation du copeau. De plus, nous pouvons valider les résultats expérimentaux en utilisant un nouveau simulateur qui est capable de prédire le comportement de la tête de perçage vibratoire en intégrant les défauts géométriques du foret.

Mots clés : Perçage / géométrie du foret / perçage vibratoire auto-entretenu / broutement

\section{Introduction}

The use of drilling in the automotive and aerospace industries increased more in more in the last 20 years. El Sonbaty et al. [1] observed that more than 10000 holes are necessary while machining an aircraft engine. In order to meet industrial demand, it is necessary to develop new techniques which can be more productive [2].

In the literature, many studies focus on improving twist drill performance during machining. Anish et al. [3] proposed to optimize the cutting edge to reduce the thrust force. Chang et al. [4] worked on the hole quality by varying the tool geometry. The study on the influence of the point angle and helix angle on generated forces during machining of composite materials has been conducted by

\footnotetext{
a Corresponding author: olcayonder@gmail.com
}

Chen [5]. Hocheng and Tsao [6] worked on five drill geometries to determine the influence of the cutting force during machining of composite materials.

All these works have showed that it is necessary to choose a tool geometry which is well suited to the operation, in order to have control on following parameters:

- the temperature generated by the cutting and friction between tool and material;

- forces generated while drilling;

- hole quality;

- tool life and machining components life [7].

Today, one of the most difficult tasks to achieve is the drilling of deep holes with small diameters. It is necessary to do scientific research to improve quality and productivity [8].

To meet these expectations, we have proposed a new technology: self-vibratory drilling. The aim is to generate 


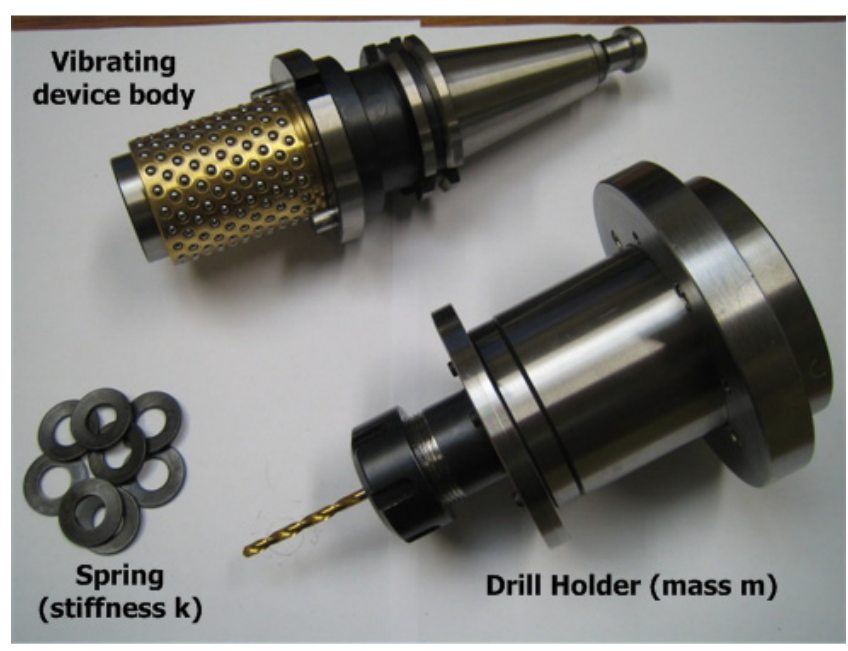

Fig. 1. Self-vibratory drilling head.

axial vibrations of the twist drill in order to get a good chip fragmentation. It becomes possible to get a good evacuation of chips without using high pressure fluid $[9,10]$. This new technique uses the cutting energy to create low frequency axial vibrations with a magnitude greater than the feed rate of the tool [11].

The self-vibratory drilling head (SVDH) (Fig. 1) is composed of three main elements:

- A part called "body" is assembled to the spindle of the machine tool with a standard attachment.

- A tool holder with a sliding connection with the base has an adjustable mass.

- An adjustable spring stiffness is placed between the body and drill holder.

The configuration (mass, stiffness) of the self-vibratory drilling head and cutting conditions are chosen based on the theory of stability lobes (Fig. 2) [12] to obtain the vibration frequency which will be resulted with a good chip fragmentation.

The use of this new technology provides increased productivity and also a reduction in production costs by eliminating the use of cutting fluid.

The tool geometry has a strong influence on SVDH performance [13]. The aim of this study is to define influence of the clearance angle, point angle and the web thickness.

\section{Experimental work}

The main purpose of this study is to find an answer to the question: "What is the influence of the tool geometry on self vibratory drilling?" To answer this question, we have realized drills with different geometrical properties. Each twist drill has been measured with an optic-laser system. They were tested with SVDH and two conditions which will give a chip fragmentation in first instability lobe. The determination of these conditions has been based on our previous works performed with
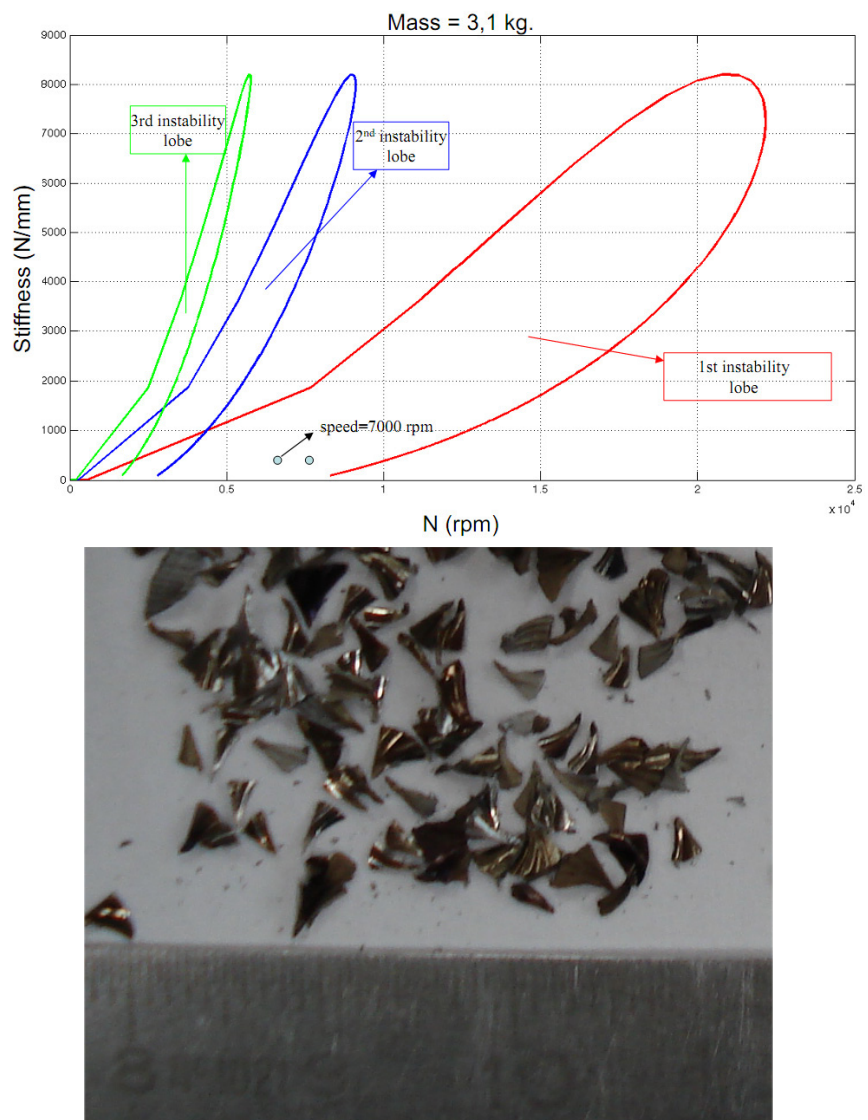

Fig. 2. Instability lobes and chip obtained after machining with SVDH.

HSS drills Tivoly reference 389 on steel 25CD4 workpiece [14]. Figure 3 shows the area where it is possible to get a chip split in primary instability lobe depending on the speed and feed rate for a given configuration of SVDH.

\subsection{Tested geometries}

We have chosen the geometry corresponding to the reference Tivoly 389 and we have changed the value of clearance angle, point angle and web thickness. Two diameters as $5 \mathrm{~mm}$ (the min diameter which have been validated with many experiments) and $2 \mathrm{~mm}$ (the limit of the currently developed SVDH) were selected and coated with TiAlN coating. An optical laser system Helicheck Plus (4 axes with 4 cameras) [15] has been used in order to determine geometrical values associated to each twist drill (Tab. 1)

\subsection{Cutting conditions and SVDH configuration}

The configuration of mass and stiffness on SVDH and determination of cutting conditions has crucial importance to have a good chip split. Based on our previous works, (Fig. 3), two rotation speeds were chosen as: $7000 \mathrm{rpm}$ and $8000 \mathrm{rpn}$ with a feed rate of $0.04 \mathrm{~mm} / \mathrm{rev}$. 
Table 1. Geometrical properties for twist drill of $5 \mathrm{~mm}$ diameter.

\begin{tabular}{|c|c|c|c|c|c|}
\hline \multicolumn{6}{|c|}{ Measured twist drill with a diameter of $5 \mathrm{~mm}$} \\
\hline & No. 1 & No. 2 & No. 3 & No. 4 & No. 5 \\
\hline Web thickness (mm) & 0.328 & 0.528 & 0.561 & 0.555 & 0.36 \\
\hline Clearance angle $\left(^{\circ}\right)$ & 5.232 & 14.868 & 13.142 & 10.998 & 7.792 \\
\hline Point angle $\left({ }^{\circ}\right)$ & 117.921 & 118.497 & 121.928 & 119.232 & 119.082 \\
\hline & No. 6 & No. 7 & No. 8 & No. 9 & No. 10 \\
\hline Web thickness (mm) & 0.56 & $\overline{0.614}$ & 0.505 & 0.574 & 0.544 \\
\hline Clearance angle $\left({ }^{\circ}\right)$ & 6.567 & 7.239 & 15.617 & 15.079 & 15.258 \\
\hline Point angle $\left({ }^{\circ}\right)$ & 118.969 & 118.365 & 119.014 & 118.638 & 118.678 \\
\hline
\end{tabular}

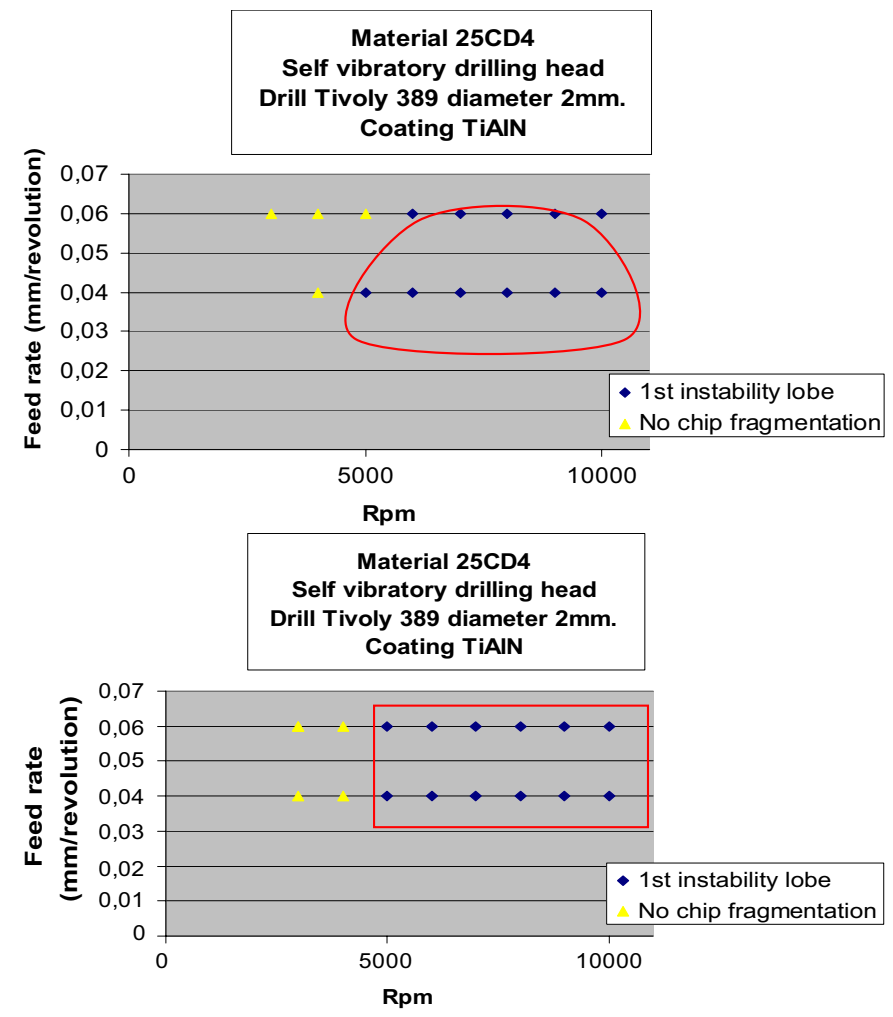

Fig. 3. Operating range.

Each test has been repeated 4 times in order to obtain consistent and repeatable results. The configuration of SVDH is given in Table 2.

\subsection{Test rig}

The tests were performed on a HERMLE C800V. Thrust forces were measured by using a Kistler dynamometer type 9367C [16] (Fig. 4).

\section{Results and discussion}

The test results indicated that some of the drills didn't give a good chip split or not a good vibration frequency in the first instability lobe. Test results related to drills with $5 \mathrm{~mm}$ diameter has been indicated at Figure 5 .
Table 2. Configuration of SVDH.

\begin{tabular}{cc}
\hline Mass of the tool holder & $\begin{array}{c}3,1 \mathrm{~kg}[1,6 \mathrm{~kg} \text { (while } \\
\text { operating with twist } \\
\text { drill diameter of } 2 \mathrm{~mm})]\end{array}$ \\
\hline Stiffness & 314 N.mm \\
\hline Coolant & Any (dry conditions) \\
\hline
\end{tabular}

The results related to the thrust forces and vibration frequency associated to each twist drill is shown in Figure 5. We have observed that twist drill number 1 is not working well and tests with twist drill number 1 resulted with no chip fragmentation. All other twist drills with diameter of $5 \mathrm{~mm}$ have given a vibration frequency between $1.42 \mathrm{vib} / \mathrm{rev}$ and $1.55 \mathrm{vib} / \mathrm{rev}$. So the chip split into parts. We have also observed that operations with twist drill number 1 have given the biggest thrust forces compared to other drill, (about 2.5 times more than other twist drill).

Tests conducted with $8000 \mathrm{rpm}$ gave similar results for twist drill number 1. (Figs. 6 and 7). But this time it wasn't possible to obtain values for the twist drill number 1 because the twist drill has been broken at the first hole. Any chip split has been observed. The obtained results for twist drill bit number 8 are interesting. For drilling speeds $8000 \mathrm{rpm}$, twist drill number 8 has not given a good performance. It didn't give a good chip fragmentation. Moreover, thrust force is bigger compared to other twist drill.

The experimental work has been continued with tests on twist drill of $2 \mathrm{~mm}$ diameter in order to be able to determine geometrical feature which has the greatest influence on the vibratory drilling (Fig. 8.)

It was known that $2 \mathrm{~mm}$ is the limit condition of SVDH's performance. While making our tests, we have seen that only 4 drills with a diameter of $2 \mathrm{~mm}$ (drill number: 1, 2, 6 and 10) can give accurate good chip split. All other 6 drill bits have been destructed during the tests.

From the obtained results, we have examined the geometries of twist drill of $5 \mathrm{~mm}$ and $2 \mathrm{~mm}$ diameters compatible with a good chip fragmentation (Tabs. 3 and 4 ).

First of all, we examine the influence of web thickness on the performance of SVDH. From the obtained results, it is difficult to conclude based on web thickness because it is not possible to determine the range of working area 

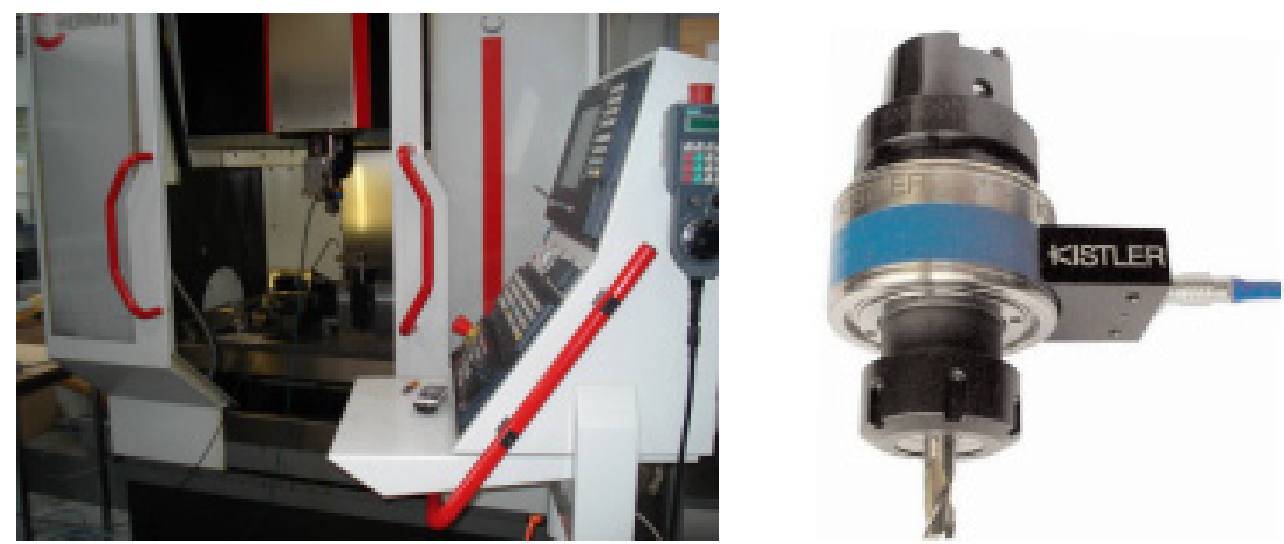

Fig. 4. Left: CU HERMLE C800. Right: Dynamometer Kistler.

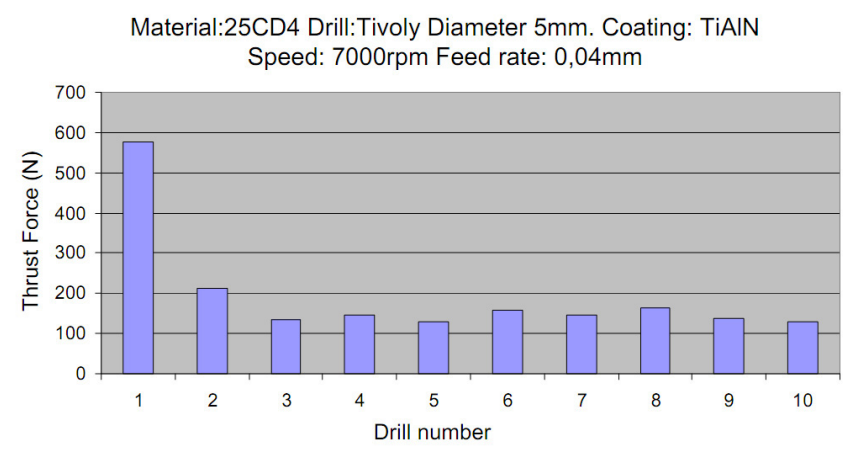

Material:25CD4 Drill:Tivoly Diameter $5 \mathrm{~mm}$. Coating: TiAIN Speed: 7000rpm Feed rate: 0,04mm

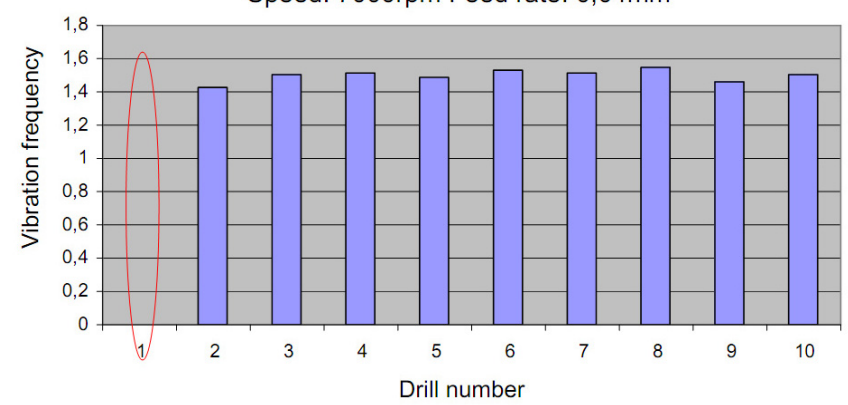

Fig. 5. Thrust force mean values and vibration frequency related to each twist drill of $5 \mathrm{~mm}$ diameter.

Table 3. Geometrical characteristics of drills with a diameter of $5 \mathrm{~mm}$ which do not give a good chip fragmentation.

\begin{tabular}{ccc}
\hline & Drill No. 1 & Drill No. 8 \\
\hline Web thickness $(\mathrm{mm})$ & 0.328 & 0.505 \\
Clearance angle $\left(^{\circ}\right)$ & 5.232 & 15.617 \\
Point angle $\left({ }^{\circ}\right)$ & 117.921 & 119.014 \\
\hline
\end{tabular}

where a good chip split happens. This conclusion has been verified for drills of $5 \mathrm{~mm}$ and $2 \mathrm{~mm}$ diameters.

Secondly, an observation on the influence of the point angle on performance of SVDH has been done. The obtained conclusion was same as the width of the lip. It is therefore difficult to identify point angle as the factor which has the greatest influence.

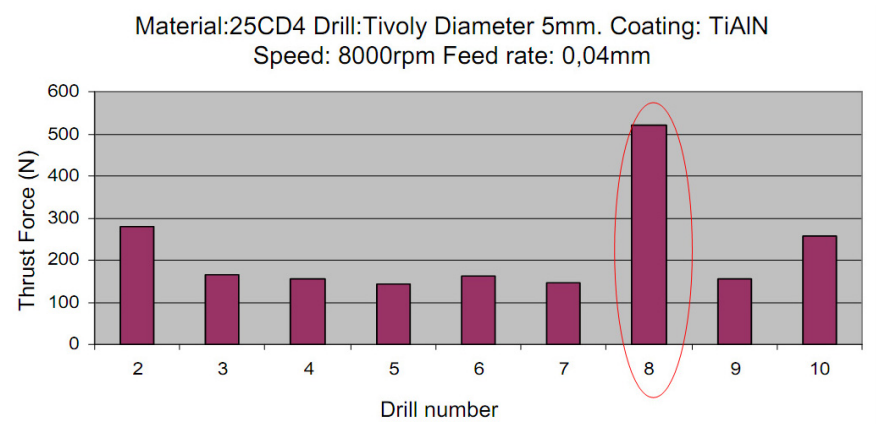

Fig. 6. Thrust force mean values related to each twist drill of $5 \mathrm{~mm}$ diameter.

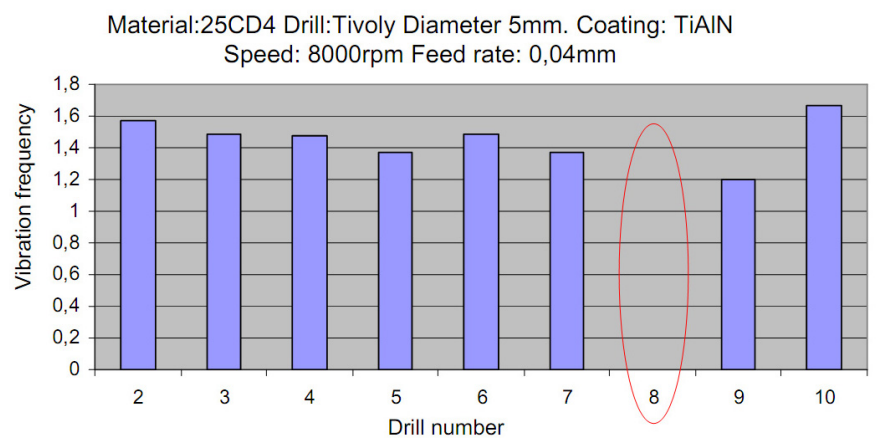

Fig. 7. Vibration frequency related to each twist drill of $5 \mathrm{~mm}$ diameter.

Material:25CD4 Drill:Tivoly Diameter $2 \mathrm{~mm}$. Coating: TiAIN Speed: 10000rpm Feed rate: 0,04mm

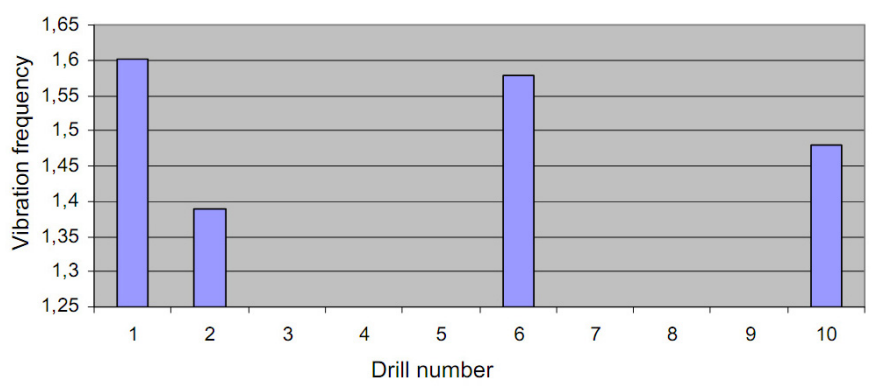

Fig. 8. Vibration frequency related to each twist drill of $2 \mathrm{~mm}$ diameter. 
Table 4. Geometrical characteristics of drills with a diameter of $2 \mathrm{~mm}$ which do not give a good chip fragmentation.

\begin{tabular}{ccccccc}
\hline Drill No. & 3 & 4 & 5 & 7 & 8 & 9 \\
\hline Web thickness $(\mathrm{mm})$ & 0.208 & 0.203 & 0.205 & 0.178 & 0.214 & 0.22 \\
Clearance angle $\left({ }^{\circ}\right)$ & 8.971 & 11.72 & 11.575 & 7.964 & 4.149 & 8.585 \\
Point angle $\left({ }^{\circ}\right)$ & 115.865 & 117.967 & 115.407 & 113.14 & 115.445 & 116.254 \\
\hline
\end{tabular}

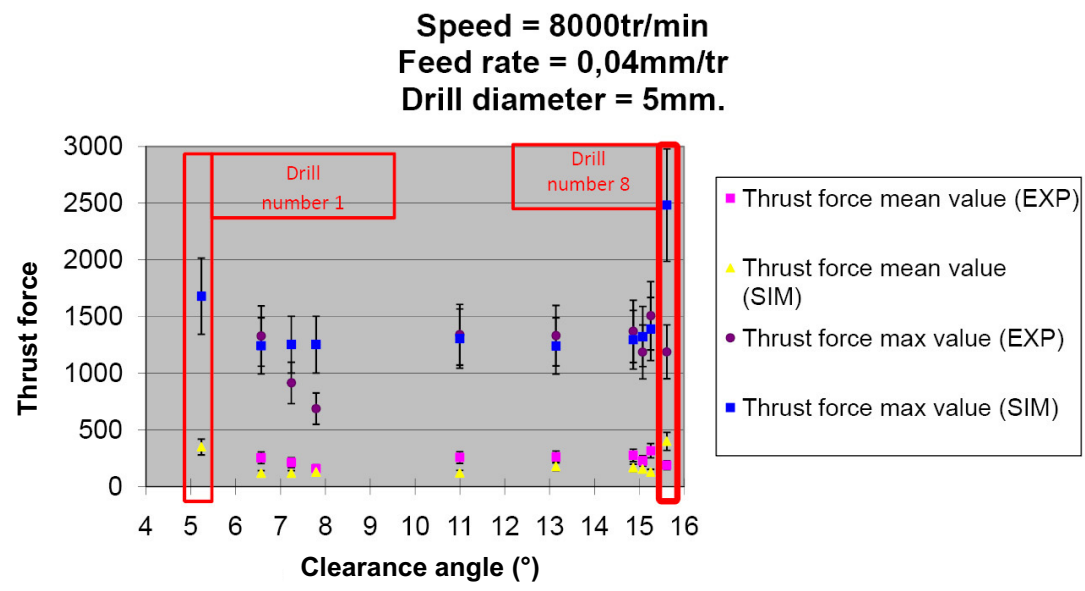

Fig. 9. Comparison between experimental and simulation results.

We can identify the clearance angle as the parameter which has the strongest influence on the dynamic behavior of SVDH. A low angle of clearance results with the absence of vibration which can be explained with the increase of damping. A significant value $\left(>15^{\circ}\right.$ for twist drill of $5 \mathrm{~mm}$ diameter) leads to a difficulty in controlling the frequency of generated vibrations. The permissible range for the clearance angle is between $6.5^{\circ}$ and $15.26^{\circ}$ for drills with a diameter of $5 \mathrm{~mm}$, which represents a large range.

Twist drill with a diameter of $2 \mathrm{~mm}$ has given a good chip split for clearance angles between $6.4^{\circ}$ and $7.9^{\circ}$.

\section{Validation by simulation}

At this study, a simulator which is capable of taking into account drill's geometrical errors has been developed. This simulator allows us to predict the dynamic behavior of self-vibratory drilling head.

To be able to simulate the process, four models has been developed and integrated into the simulator:

- A dynamic model of SVDH [17];

- A geometrical model of drill [11];

- A thrust force model [11];

- A model of material removal process and generation of machined shape [17].

Selected simulation configuration is identical to the experimental conditions. As we have identified the clearance angle as the parameter which has the biggest influence on SVDH behavior, we vary this angle. The point angle and the web thickness have been considered as fixed values as $0.487 \mathrm{~mm}$ and $120.14^{\circ}$.

Thrust force comparison between experimental and simulation has been given at Figure 9 for drills of $5 \mathrm{~mm}$ a diameter.
We have obtained similar results between experimental and simulation work. It has been observed that the drills which do not give a good performance have given the biggest thrust force values on simulation results and on experimental results. The vibration frequency obtained by simulation is very close to that measured during the experiments. We have also found similar good working ranges (a good chip fragmentation) by the terms of clearance angles.

\section{Conclusions}

A study to determine the influence of the twist drill geometry on machining with self-vibratory drilling has been done. Results showed that the clearance angle has the most influence on the dynamic behavior of SVDH. Moreover, the permissible range for the clearance angle is narrower when the diameter of the twist drill decreases.

To optimize the twist drill geometry and the configuration of SVDH, we have developed a new simulator which is capable of taking into account geometrical errors of the twist drill. Very close results between experimental work and simulations has been observed.

Acknowledgements. This work has been done as a part of thesis CIFRE with company CTDEC and the project FUI "Forage Grande Vitesse Vibratoire".

\section{References}

[1] I. El-Sonbaty, U.A. Khashaba, T. Machaly, Factors affecting the machinability of GFR/epoxy composites, Compos. Struct. 63 (2004) 329-338 
[2] M. Nalbant, A. Altin, H. Gokkaya, The effect of cutting speed and cutting tool geometry on machinability properties of nickel-base Inconel 718 super alloys, Materials and Design 28 (2007) 1334-1338

[3] A. Paul, S.G. Kapoor, R. Devor, Chisel edge and cutting lip shape optimization for improved twist drill point design, Int. J. Machine Tools \& Manuf. 45 (2005) 421-431

[4] S.L. Ko, J.E. Chang, Development of drill geometry for burr minimization in drilling, school of mechanical and aerospace engineering, Konkuk University, Saoul Korea

[5] W. Chen, Some experimental investigations in the drilling of carbon fibre-reinforced plastic (CFRP) composite laminates, Int. J. Machine Tools \& Manuf. 37 (1997) 10971108

[6] H. Hocheng, C.C. Tasao, Effects of special drill bits on drilling-induced delamination of composite materials, Int. J. Machine Tools \& Manuf. 46 (2006) 1403-1416

[7] A.M. Abrao, J.C. Campos, P.E. Faria, J.P. Davim, The effect of cutting tool geometry on thrust force and delamination when drilling glass fibre reinforced plastic composite, Materials and Design 29 (2008) 508-513

[8] A. Velayudham, R. Krishnamurthy, Effect of point geometry and their influence on thrust and delamination in drilling of polymeric composites, J. Mater. Proc. Technol. 185 (2007) 204-209

[9] S. Tichkiewitch, G. Moraru, D. Brun-Picard, A. Gouskov, Self-excited vibration drilling models and experiments, Annals of the CIRP 51 (2002) 311-314
[10] S. Tichkiewitch, H. Paris, G. Peigne, Modelling the vibratory drilling process to foresee cutting parameters, Ann. CIRP 54 (2005) 367-370

[11] N. Guibert, Étude et modélisation des phénomènes de coupe sur les performances du forage vibratoire, Thèse de doctorat, Université Joseph Fourier, Grenoble 1, 2008

[12] Y. Altintas, Manufacturing Automation (Cambridge University Press) 2000

[13] N. Guibert, H. Paris, J. Rech, Influence of the chisel edge geometry on the vibratory drilling behaviour, In High Speed Machining Congress, San Sébastian, 2007

[14] P. Naisson, J. Rech, L. Grenier, H. Paris, Influence du matériau pièce sur le domaine de fonctionnement $\mathrm{du}$ perçage vibratoire, $11^{\mathrm{e}}$ Colloque National AIP PRIMECA La Plagne, 22-24, 2009

[15] Walter Machines Helicheck Plus http://www . walter-machines.com/fr/produits/ mesure/helicheck-plus.html

[16] Kistler Capteurs Dynanometers http://www.kistler. com/mediaaccess/9367C_000-613e-04.07.pdf

[17] Ö.Olcay, Extension de la technique de perçage vibratoire à des matériaux difficiles à usiner et au domaine du décolletage, Thèse de doctorat, Université Joseph Fourier, Grenoble 1, 2011 